\title{
The complex story of energy transition -an introduction
}

\author{
F. WAGNER $(*)$ \\ Max-Planck Institut für Plasmaphysik - Garching/Greifswald, Germany
}

Human beings grew in numbers as any other biological system would do under favourable living conditions. The growth of mankind up to presently 7.5 bn people was enabled by the access to cheap energy. Technology made it possible to exploit fossil fuels at large scale and to transform the chemically bound energy into different forms for practical application.

Figure 1 shows the growth of the US population between 1835 and 2009. Initially, at still a small population, the renewable energy (RE) share in the energy demand was high, close to 1 . In course of time, the share of nuclear and fossil energy grew at the expense of REs. This historical evolution is representative for most industrialised countries. The interrelation between energy consumption by a growing population and the population growth by energy availability is, however, not "free lunch".

Figure 2 shows the increase of world energy consumption being steeper than the growth of world population. However, about $80 \%$ of primary energy use gives rise to $\mathrm{CO}_{2}$ emissions. Mankind is suddenly faced with the threat of climate change. In the future, the course has to be reversed back to large RE shares but under conditions where large populations, 300 Mill people in case of USA (see fig. 1), have to be safely and economically supplied by energy.

As nutrition, clean water, healthy living conditions all depend on access to energy a classical conflict emerged in the last decade between efforts to locally improve living conditions by higher energy use and the threat of thereby jeopardising the global living conditions if energy consumption causes $\mathrm{CO}_{2}$ release in the atmosphere as is the case up

$\left(^{*}\right)$ E-mail: fritz.wagner@ipp.mpg.de 


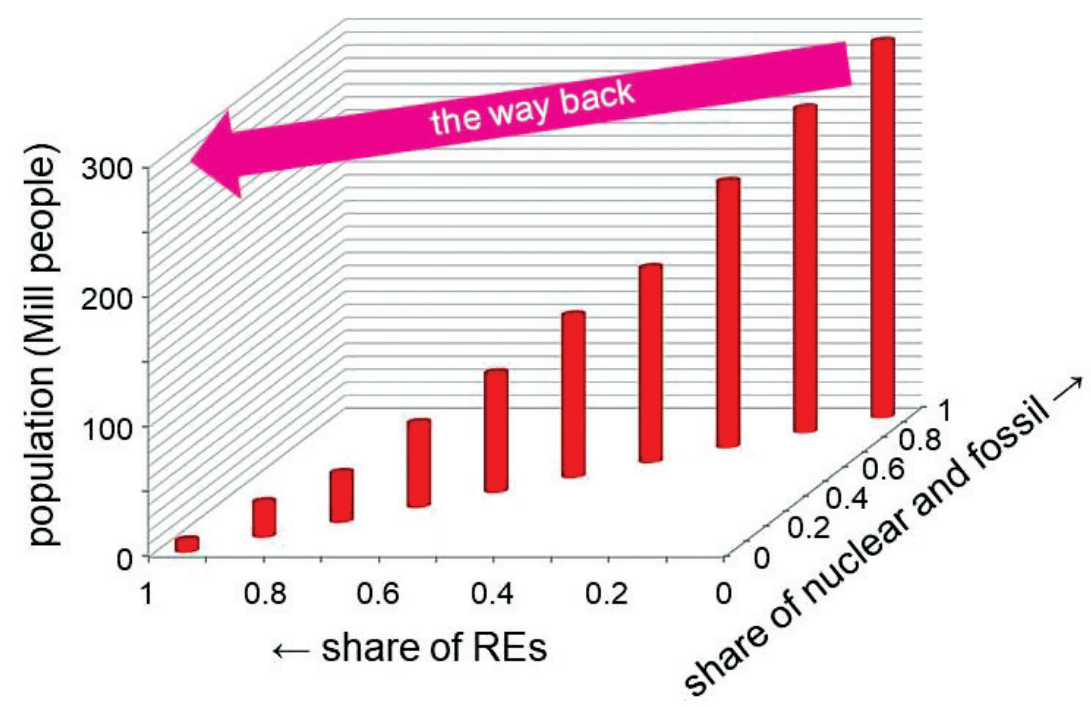

Fig. 1. - Growth of the US population between 1835 and 2009 plotted against the share of renewable, nuclear and fossil energy.

to now. Figure 3 shows the human development index HDI, based on life expectation, education, and gross domestic product (GDP) together with the "life expectation at birth" versus the electricity consumption per capita. There is a close correlation - more electricity, or generally energy, allows a better and healthier life. These relations drive

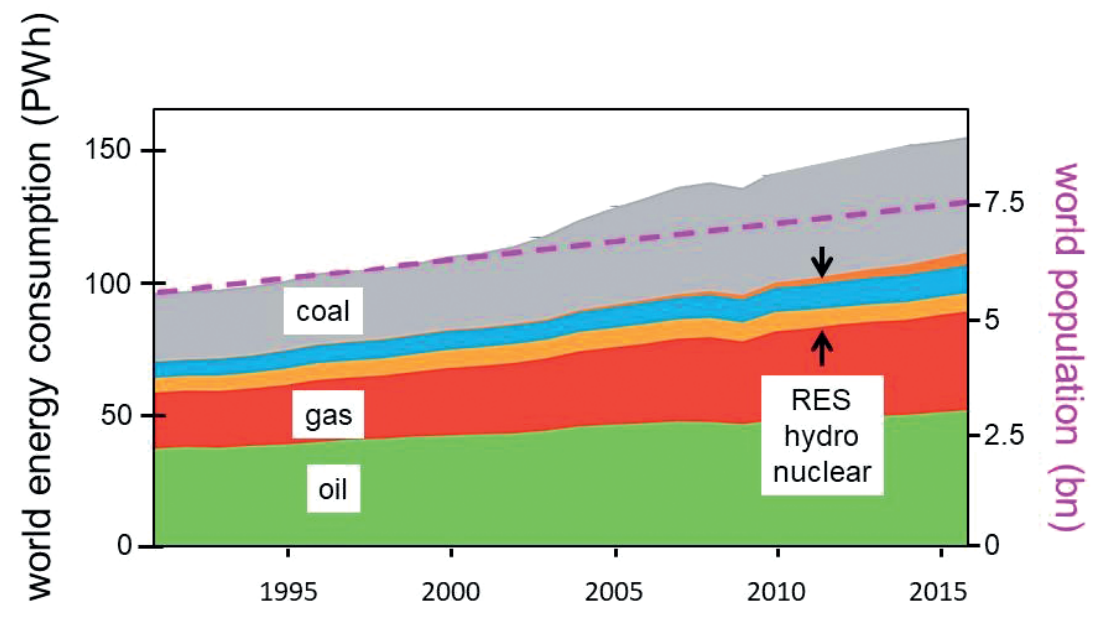

BP Statistical Review of World Energy June 2017

Fig. 2. - Growth of world energy consumption and of world population. 


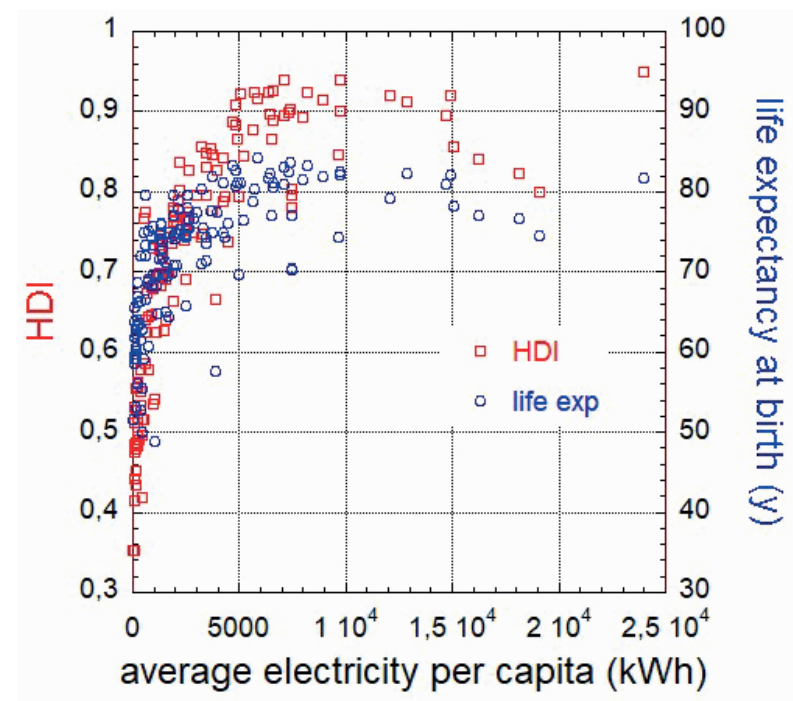

Fig. 3. - Human development index HDI, and "life expectation at birth" versus the electricity consumption per capita.

the world to higher energy production and consumption and it has to be expected that this development continues as governments have constitutionally the task to improve the welfare of their nations.

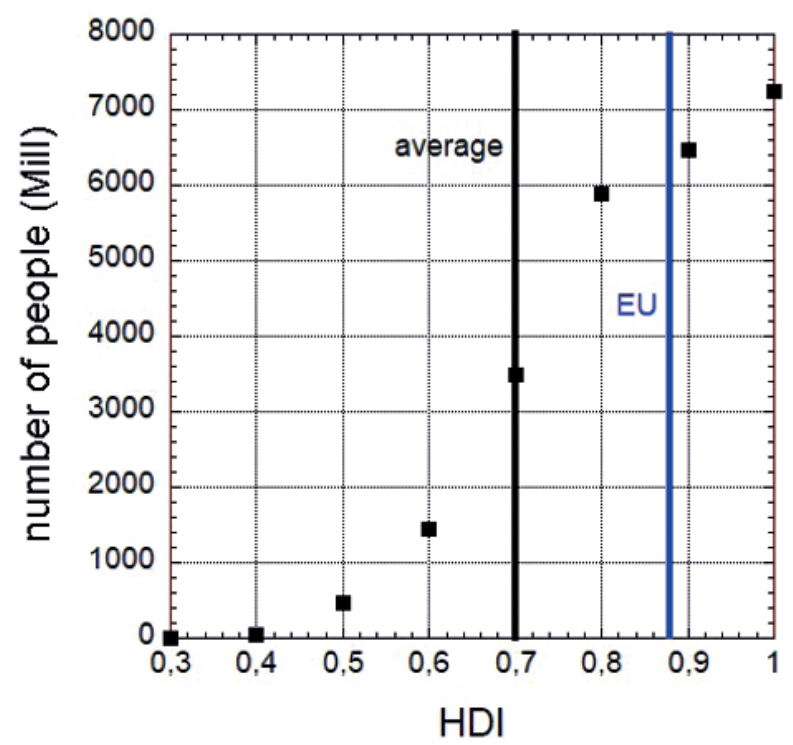

Fig. 4. - Number of people living below a specified HDI value. 


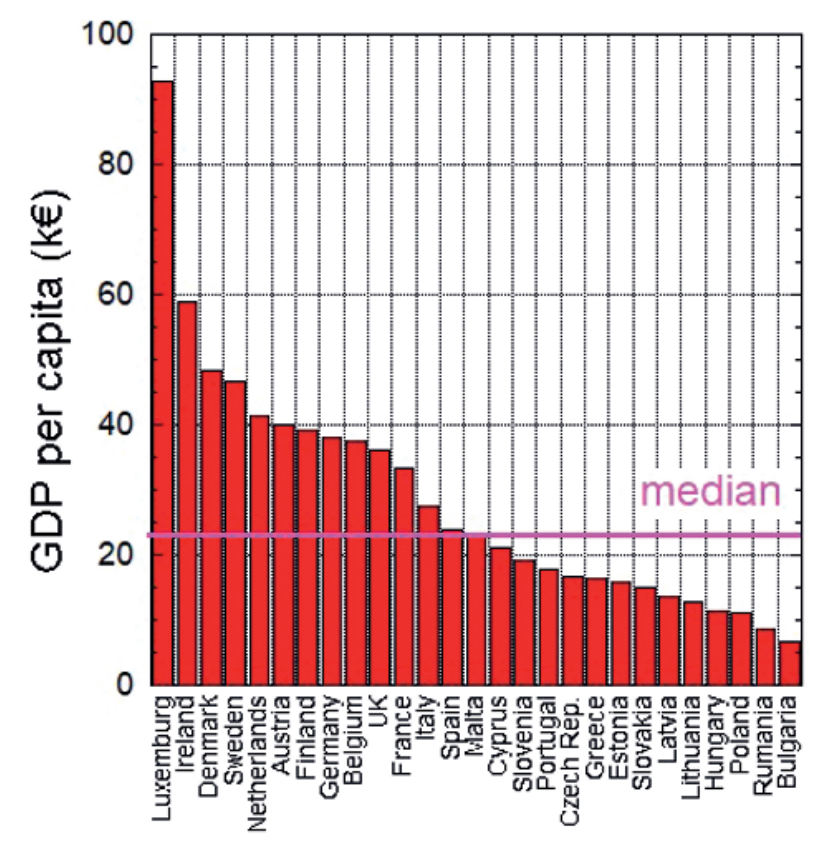

Fig. 5. - Distribution of the GDP per person in Europe.

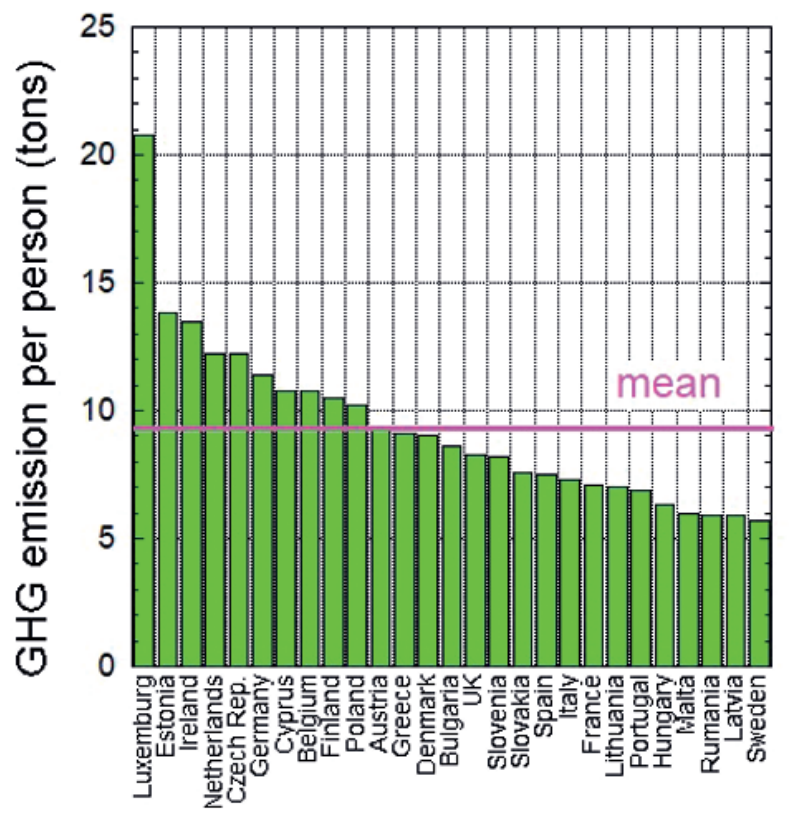

Fig. 6. - Per capita GHG emission for the different EU countries. 
Figure 4 analyses the number of people on earth enjoying high HDI factors - or not, respectively. The average HDI value and the one of the EU are indicated by vertical bars. About 6.5 Mill people live under circumstances below the average standard of Europe. This aspect should be the source of much concern because tremendous societal upheavals can be expected when this distribution of welfare expands toward a more homogeneous and just distribution specifically if the future promises energy scarcity out of environmental concerns.

Europe offers unfavourable conditions for an energy transformation process toward less $\mathrm{CO}_{2}$ emission. Figure 5 shows the distribution of the GDP per person, the economic productivity of different European countries. There is a large spread by a factor of 15 in wealth within the European countries, which can be expected to be an obstacle if the transformation process of energy technologies enforces sacrifices and abdication of accustomed life-style.

As we have seen above for the global situation, the variation in GDP in Europe reflects itself in a corresponding variation in primary energy (PE) use and in greenhousegas (GHG) emission, as demonstrated by fig. 6. Plotted is the per capita GHG emission for the different EU countries. In tendency, those countries with a large GDP per capita are individually also causing large GHG emissions. E.g., Germany, the most populated European country, gains its wealth at the expense of a large GHG footprint. But there

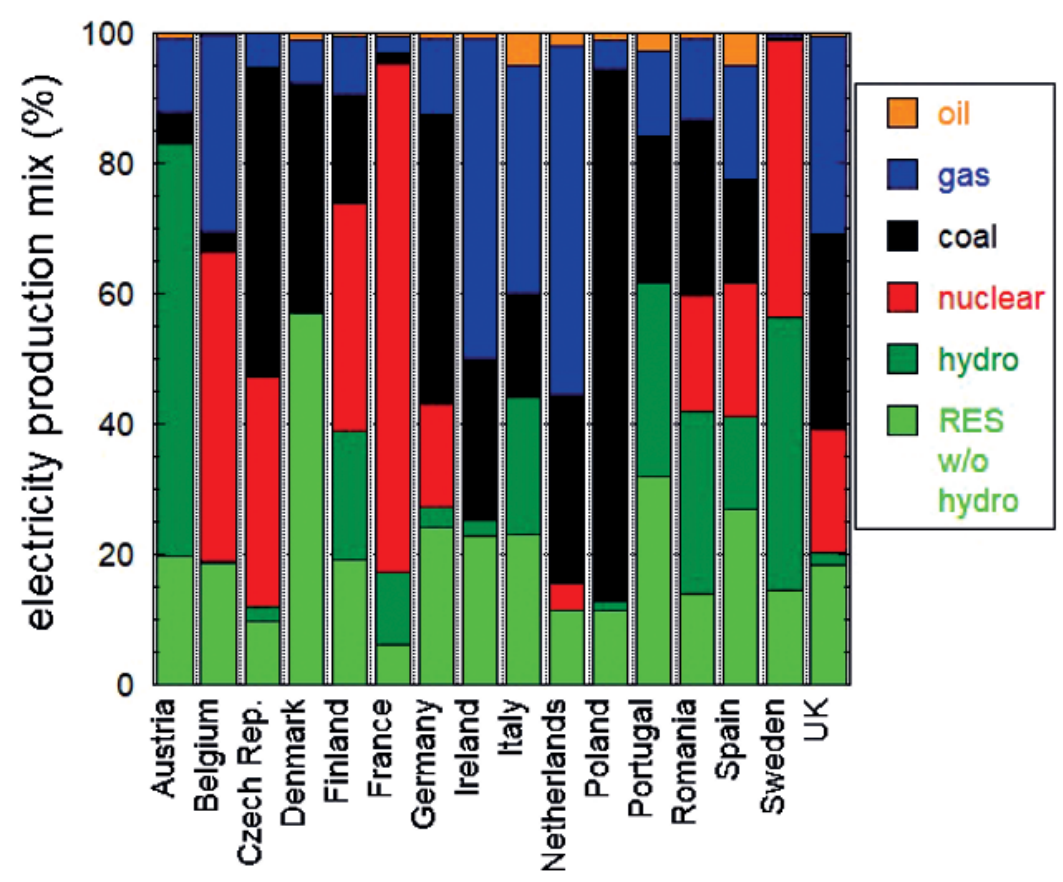

Fig. 7. - Sources of electricity production of European countries. 
are deviations from this rule notably Sweden and France with high GDPs at low GHG emission. Those cases have to be studied in some detail and they might provide a specific message how to properly guide the transition.

But Europe will be an interesting test bed for the energy transition thanks to its strong national diversification in electricity production today, as fig. 7 shows. Poland is nearly $80 \%$ coal based in its electricity generation, France nearly $80 \%$ nuclear and Austria, thanks to a large hydro share, more than $80 \%$ renewable.

It is obviously easy to collect the European countries behind formal climate goals. Europe has formulated common energy and climate targets, e.g., up to 2030 - to reduce GHG emission by $40 \%$ compared to 1990 , to increase the REs share to $27 \%$ and to improve energy efficiency by $27 \%$. But it will be a tremendous political task to collect these countries behind these goals as soon as the process boils down to decide upon suitable $\mathrm{CO}_{2}$-free technologies. This book presents and discusses many technical solutions. But in principle, there are not so many and they all have or may have caveats. Most of the technologies produce electricity, which will be the primary energy of the future from which other forms of energy have to be derived - least efficient and powerful storage technologies can be developed so that electricity can serve all energy consuming sectors including mobility, room- and process heat. But this exclusiveness should not be expected because also local circumstances as the availability of geo-thermal or solar-thermal energy will play a role (or does it already now).

The future nuclear technologies are fission on the basis of fast neutrons, developed in the frame of Generation IV reactors and fusion, with ITER being the first, still experimental, fusion reactor presently realised in France. The problems of fission are well known - predominantly concerns about safety and radioactive waste. It may make a difference whether a country never accumulated fission waste because it did not use fission energy. In the other case, a storage technology has to be developed and a repository for waste has to be identified. This is unavoidable. In this case, the quantity of waste to be handled is of minor importance.

Unfortunately, fusion is not ready and will not play a role up to mid of this century where a solution for the climate problem has to be found and implemented. Fusion promises favourable supply and environmental characteristics and radioactive waste with short decay times (about 100 years). Around 2035, ITER will demonstrate the soundness of the fusion concept from the physics and partly the materials point of view.

The use of fossil fuels can in principle be continued but in the frame of carbon-capture and sequestration (CCS) where $\mathrm{CO}_{2}$ is collected and separated and finally stored in underground cavities.

Finally, there are many renewable energy forms with proven or expected capabilities - wind and solar power and bio-mass may offer the best prospects. But each has specific characteristics and problem areas like low power density, intermittency in case of wind and photovoltaic (PV) power or the general concerns in case of biomass about nutrition and losses of bio-diversity. Material to these topics is presented in these proceedings.

Because of the environmental concerns, fossil energy supply technologies have to be replaced by new techniques without $\mathrm{CO}_{2}$ emission in the short period of about one 


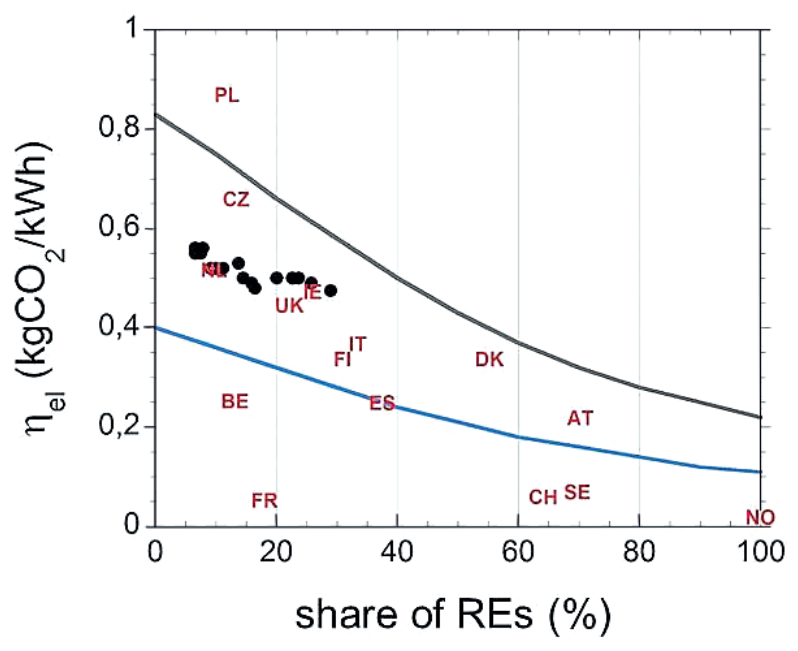

Fig. 8. - Specific $\mathrm{CO}_{2}$ emission versus the share of renewable energies involved in electricity generation. Black dots: German development from 2002 to 2015. The black curve represents an upper limit - Germany's electricity is produced with the present mix of fossil fuels. The blue curve represents the case that Germany's electricity is produced by gas. The country symbols represent the situation of different European countries.

generation. But in this period the number of energy consumers will increase by further 2.5 bn aggravating the complexity of a world-wide technology change. In the past, the time scales for a technology change were specified by the resources of fossil fuel, e.g., 50 years for gas and oil, about 120 years for coal whereas the shale oil and gas bonanza in the USA demonstrated that these figures are lower estimates and that the Hubbard peak has the tendency to move further into the future. The new time scales are by far more restrictive with the tendency to rather move closer. The "new" timescales are dictated by the 2-degree limit and the remaining possible $\mathrm{CO}_{2}$ pollution. If the world would pollute the atmosphere with $\mathrm{CO}_{2}$ as the average American does, the limit would be reached in about 8 years; it would be reached in about 75 years with the average Indian emission and with the one of the average European, it would be met in 16 years. Time is short now; nevertheless, the global development may not be encouraging. On the one hand there are pompous climate meetings, on the other hand, it was demonstrated how quickly climate policies can change in democracies, e.g. after an election. Also the developments in Europe are not convincing. The main and most meaningful concept - to give an increasing price to the emission of $\mathrm{CO}_{2}$ - has not successfully been implemented. Despite tremendous efforts for the energy transition in Germany where the wind and PV capacity surpasses already the peak electricity power demand, the GHG emission has not been reduced in a convincing way. Germany also demonstrates the high price tag for the technology change with the highest electricity prices in Europe. France rules out CCS by law. On the other side, coal will not disappear quickly and the last cold winter and fuel 
crisis in China will have left their mark. About $70 \%$ of Chinas electricity is generated by burning coal and China develops and exports coal power plants with higher efficiency and lower emission. It would be wise to use the European expertise and culture in technology development and research to contribute to all energy relevant fields, including CCS.

This applies also to research into future fission concepts. Unfortunately, fission has become a field for party politics which ignore the demonstrated capability of this technology. Figure 8 shows the specific $\mathrm{CO}_{2}$ emission connected with electricity production first for Germany (black dots, black and blue curves) and for different European countries (country symbols). The black dots show the German development from 2002 to 2015 where a fleet of RE systems has been built up. The black curve represents an upper limit for the hypothetical case that the German electricity production happens exclusively with the present mix of fossil fuels (coal, lignite and gas). The actual data fall below this curve mostly thanks to nuclear power. The blue curve represents the other hypothetical limit that electricity in Germany is exclusively produced by gas. Of interest are the points of other countries falling below the blue limit: Norway thanks to hydro power and the other countries thanks to their hydro and nuclear power mix. France has nearly $80 \%$ electricity from nuclear power, Belgium nearly 50\%, Sweden and Switzerland about $40 \%$. If Europe is truly concerned about global warming and climate change, these figures and facts cannot be ignored. Even with 100\% REs, Germany will not reach the low level of $\mathrm{CO}_{2}$ emission of countries which involve nuclear power least a $\mathrm{CO}_{2}$-free back-up system is available to bridge periods without wind during the night. In summary, some EU countries have produced electricity already at a low $\mathrm{CO}_{2}$ emission level for 35 years which Germany plans to meet in 35 years.

This chapter should demonstrate that a solution of the climate problem -if possible at all for 10 bn people on earth - can only come from technology and can only be implemented by adhering to the rules and laws of economy. Therefore, research is mandatory into all energy related fields with good prospects. It might be profitable for political parties to rule out research into fields which do not agree with ideological positions but this is a dangerous route for their nations. With insufficient and wrong technology a reduction of GHG emission might nevertheless be possible by the deindustrialisation of Europe. Its effectiveness has been demonstrated by the reduction of the German GHG emission following the deindustrialisation of the former DDR starting in 1990, by the effects of the economic crises of 2008/2009, or by the creeping deindustrialisation in several European countries. This may not be the way the European young generation might favour. This book collects facts on energy technologies and issues addressing young scientist which will soon have a say when it comes to decisions on energy politics. This book should provide a sound technical basis. 